\title{
SMART TOILET FOR BLIND PEOPLE (SMARTOBLIN) INOVASI ALAT BANTU MOBILITAS TUNANETRA DI KAMAR MANDI
}

\author{
Raden Budi Santoso ${ }^{1}$, Wahyuni Amilya ${ }^{2}$, Ikhsan Sahida ${ }^{3}$, Ariadie Chandra Nugraha ${ }^{4}$ \\ ${ }^{\mathbf{1 , 3 , 4}}$ Jurusan Pendidikan Teknik Elektro, ${ }^{2}$ Jurusan Pendidikan Luar Biasa \\ email: radenbudi65@gmsil.com
}

\begin{abstract}
The implementation of this PKM uses the Linear Sequential Model (NGO) method which consists of four repetitive stages, namely the analysis and study of literature, system design / design, assembly-electrics systems, and testing. The objectives of the PKM implementation are: 1) to produce the Smart Toilet for Blind People (SMARTOBLIN) design of innovative visual aids to increase independence in the bathroom, 2) to understand the SMARTOBLIN work system, and 3) to know the advantages and benefits of SMARTOBLIN for persons with hostingnetra. PKM implementers develop SMARTOBLIN according to the needs of blind people. The output is in the form of audio that will direct blind people in activities in the bathroom. Information that will be received by the blind in the form of speaker notification sound: 1) Bathroom for men or women, 2) Information on the location of objects in the bathroom, 3) warning to always be careful because the condition of the floor is slippery, and 4) information whether the bathroom is filled or empty. The advantages and benefits of SMARTOBLIN are examined quantitatively and qualitatively. The quantitative results obtained through questionnaires get $85 \%$ results with a very feasible category. For the qualitative description of blind people, the innovation is very useful because it makes it easy for blind people to recognize objects in the bathroom without having to do long trailing.
\end{abstract}

Keywords: audio, bathroom, blind

\begin{abstract}
ABSTRAK
Pelaksanaan PKM ini menggunakan metode Linear Sequential Model (LSM) yang terdiri dari 4 tahapan yang berulang yaitu tahap analisis dan studi literatur, desain/perancangan sistem, perakitan sistem elektronik (assembly-electrnics systems), dan pengujian. Tujuan dari pelaksanaan PKM ini adalah: 1) menghasilkan rancangan Smart Toilet for Blind People (SMARTOBLIN) inovasi alat bantu tunanetra guna meningkatkan kemandirian di kamar mandi, 2) mengerahui sistem kerja SMARTOBLIN, dan 3) mengetahui keunggulan dan kebermanfaatan SMARTOBLIN bagi penyandang tuannetra. Pelaksana PKM mengembangkan SMARTOBLIN sesua dengan kebutuhan tunanetra. Output yang dihasilkan berupa audio yang akan mengarahkan penyandang tunanetra dalam beraktivitas di kamar mandi.Informasi yang akan diterima oleh tunanetra berupa notifikasi bunyi speaker: 1) Kamar mandi untuk laki-laki atau perempuan, 2) Informasi letak benda di kamar mandi, 3) peringatan untuk selalu berhati-hati karena kondisi lantai licin, dan 4) informasi apakah kamar mandi terisi atau kosong. Keunggulan dan kebermanfaatan SMARTOBLIN ditelaah secara kuantitatif dan kualitatif. Adapun hasil kuantitatif diperoleh melalui kuesioner mendapatkan hasil $85 \%$ dengan kategori sangat layak. Untuk deskripsi kualitatif penyandnag tunanetra mengatakan bahwa inovasi ini sangat bermanfaat karena memudahkan tunanetra dalam mengenali benda di kamar mandi tanpa harus melakukan trailing yang lama.
\end{abstract}

Kata kunci : audio, kamar mandi, tunanetra

\section{PENDAHULUAN}

Indra penglihatan mempunyai peran penting dalam kehidupan sehari-hari. Sebagian besar, seseorang dapat mengetahui berbagai informasi atau konsep dengan cara melihat (Suharmini, 2009: 30). Namun, hal tersebut tidak berlaku pada mereka yang mengalami hambatan penglihatan sejak lahir. Anak dengan hambatan penglihatan (tunanetra) sejak lahir seringkali mengalami kekurangan konsep-konsep dasar dan gagal untuk memaknai komponenkomponen penting suatu informasi dari lingkungan sekitarnya. Sehingga dibutuhkan 
kompensatoris berupa Braille dan Orientasi Mobilitas (OM) agar kekurangan yang disebabkan hilangnya fungsi pengelihatan dapat dialihkan dengan mengoptimalkan fungsi tubuh yang lain. Tunanetra adalah seseorang yang memiliki ketajaman visual kurang dari 20/200 dan jarak sudut pandang tidak lebih dari 20 derajat (Daniel P. Hallahan, 2009: 80).

Selain memperoleh layanan kompensatoris, tunanetra berhak mendapatkan penyediaan fasilitas berupa sarana dan prasarana yang membantu aktivitas mereka. Faktanya hal ini masih diabaikan. SLB A Yaketunis yang beralamat di Yogyakarta sejatinya merupakan sekolah khusus tunanetra namun fasilitas kamar mandi yang ada belum aksesibel untuk tunanetra karena: 1) belum terdapat petunjuk atau yang membedakan kamar mandi laki-laki dan perempuan, 2) belum terdapat kemudahan bagi tunanetra untuk membedakan kamar mandi yang kosong dan yang diisi, 3) kondisi kamar mandi yang licin akan berbahaya jika menimbulkan korban yang terpleset. Padahal kebutuhan akan kamar mandi dan simbol (petunjuk) umum sangat diperlukan.

Hal ini diperkuat dengan ditetapkannya Peraturan Menteri Pekerjaan Umum NOMOR : 30 / PRT / M / 2006 "Pedoman Teknis Fasilitas dan Aksesibilitas pada Bangunan Gedung dan Lingkungan" mengenai penyediaan fasilitas dan aksesibilitas prasarana dan sarana pada bangunan gedung dan lingkungannya. Hal ini mengartikan bahwa meskipun keterampilan orientasi dan mobilitas tunanetra sudah baik tetap saja mereka memerlukan kemudahan petunjuk dalam bergerak berupa clue seperti rangsangan visual, auditoris, kinestetik, ransangan taktual, aroma, suhu. (Rahadja. 2010). Selain itu salah satu kecelakaan yang berbahaya namun sering kali kita abaikan adalah kecelakaan di kamar mandi. Padahal menurut Center for disease Control and Prevention (CDC) di AS, ada sekitar 235.00 orang berusia 15 tahun ke atas yang dirujuk ke unit gawat darurat karena mengalami cidera di kamar mandi setiap tahunnya. Hal ini karena lantai yang licin, stop kontak yang terlalu dekat dengan air, dan tidak adanya tiang pegangan di toilet (detikhealth, 2012).

Pemerintah Indonesia sedang berbenah dalam upaya pemenuhan hak difabel sesuai dengan UU Nomor 8 Tahun 2016 baik dalam hak ekonomi, politik, sosial dan budaya. Seperti membuat toilet ramah difabel yang berlokasi di Monas. Toilet ini sudah dilengkapi handle dan wastafel. (Kumparan.com.2017). Selain pemerintah, mahasiswa Institut Teknologi Nasional Malang juga bersumbangsih membuat karya tentang Pengembangan Model Kamar Mandi Bagi Penyandang Tunaneta. Faktanya, toilet ini belum cukup aksesibel bagi tunanetra, karena belum dilengkapi dengan akses suara yang dapat menjelaskan keberadaan objek.

Melihat pentingnya akses mobilitas di kamar mandi bagi penyandang tunanetra, maka dari itu inovasi teknologi yang bernama SMARTOBLIN (Smart Toilet for Blind People) Inovasi Alat Bantu Tunanetra guna Meningkatkan Kemandirian Aktivitas di Kamar Mandi dibuat. Tim PKM mengembangkan SMARTOBLIN sesuai dengan kebutuhan penyandang tunanetra.

\section{METODE}

Pelaksanaan pengembangan alat ini dilakukan dengan berbagai tahapan mengikuti model Linear Sequential Model (LSM) yang terdiri dari 4 tahapan terdiri atas tahap analisis dan studi literatur, desain/perancangan sistem, perakitan sistem elektronik (assembly-electrnics systems), dan pengujian.

\section{Analisis dan study literature}

Dalam tahapan ini, telah dilaksanakan analisis dan studi literature pada hari Selasa, 9 April 2019 secara manual dengan mewawancarai 3 orang subjek tunanetra di asrama SLB A Yaketunis yang beralamat Jl. Parangtritis 46, RT/RW 66/18, Dsn. Danunegaran, Ds./Kel Mantrijeron, Kec. Mantrijeron, Kota Yogyakarta, Prov. D.I. Yogyakarta. Hasil yang didapat adalah di kamar mandi biasa mereka sudah biasa 
melakukan orientasi sendiri namun di kamar mandi yang baru mereka kesulitan untuk membedakan kamar mandi wanita atau lakilaki, serta kamar mandi yang sedang terpakai atau tidak secara mandiri. Maka dari itu tidak ada pilihan informasi letak kamar kecuali meminta bantuan orang lain untuk menunjukkan keberadaan kamar mandi tersebut. Setelah sampai di kamar mandi yang ditunjukkan mereka akan melakukan orientasi sendiri secara manual dengan cara meraba-raba maupun menggerak-gerakkan kaki untuk mengenali posisi benda yang ada di kamar mandi.

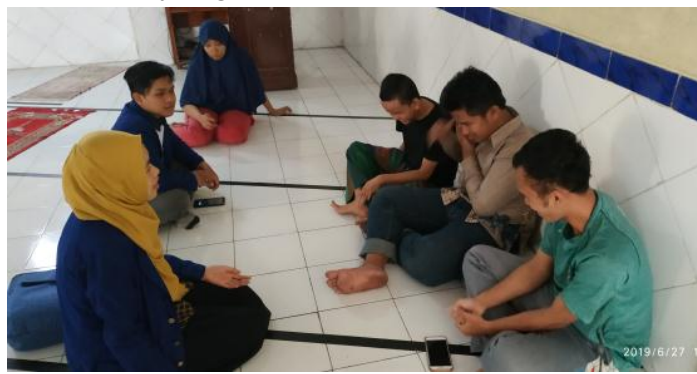

Gambar 1. Wawancara dengan penyandang tunanetra di asrama SLB A Yaketunis.

\section{Desain / Perancangan Sistem}

Pada tahap ini telah dikembangkan cara kerja dari SMARTOBLIN (Smart Toilet for Blind People). Pengembangan dilakukan dalam bentuk program yang digunakan sebagai perintah dalam mikrokontroller dengan baik. Secara garis besar sistem hanya terdiri dari tiga bagian berupa input, proses dan output yang dicirikan dengan sensor motion manusia yang mempunyai output audio.

Tahap pengkodean setelah dilakukan rancangan desain kemudian diterjemahkan menjadi progam guna memproses sinyal input yang masuk dari setiap sensor ke dalam mikrokontroller (arduino), sehingga menghasilkan output berupa audio yang berisikan informasi guna memandu penyandang tunanetra untuk memudahkan mobilitas ketika berada di kamar mandi. Langkah pengkodean ini dilakukan menggunakan laptop maupun computer yang telah di install software CVAVR.

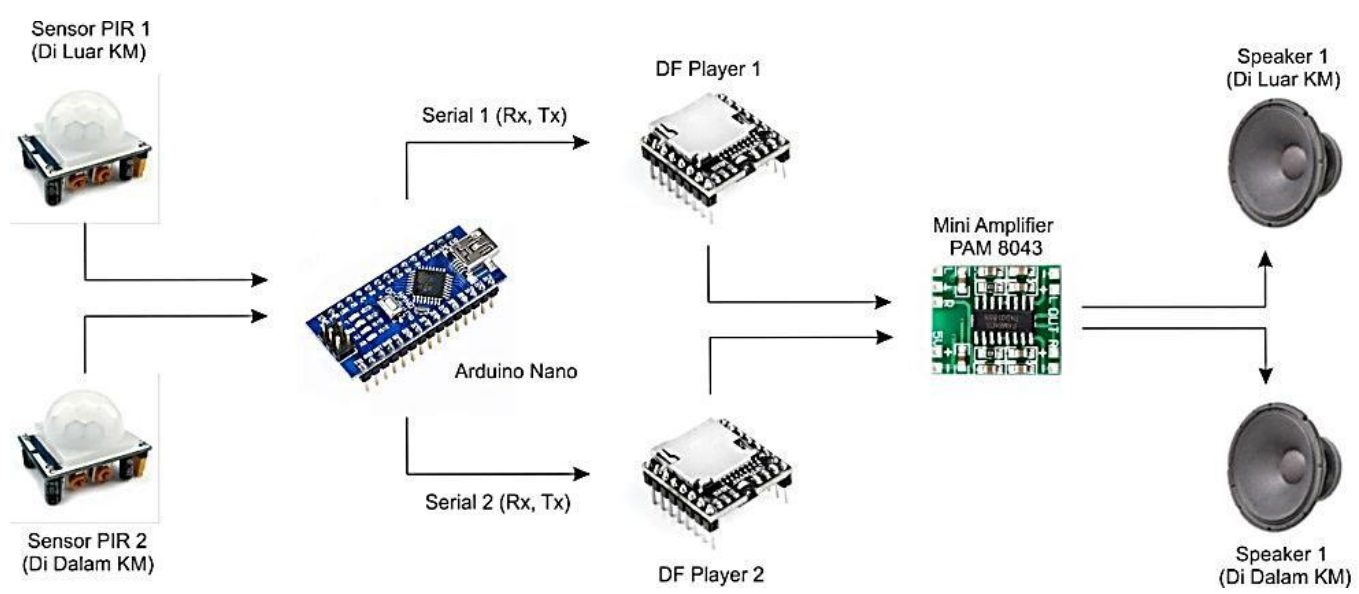

Gambar 2. Diagram blok Smartoblin 


\section{Tahap Pembuatan dan Perakitan dan Sistem Elektronik}

Pada perakitan system elektonik peneliti telah menempatkan komponennya seperti Sensor PIR 1 terletak pada dinding kamar mandi yang penempatannya dapat disesuaikan dengan arah jangkauan terdekat tunanetra dari ke dalam kamar mandi.

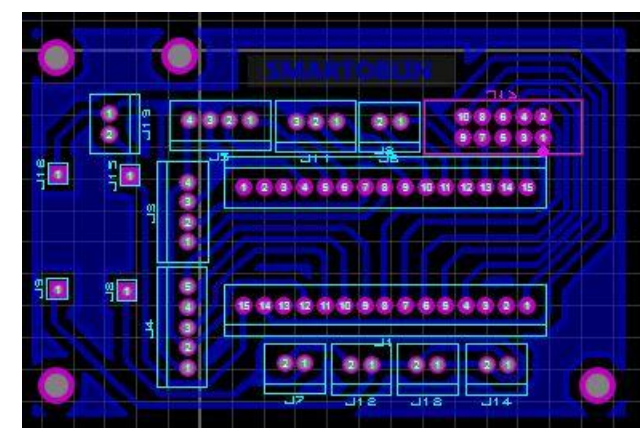

Gambar 2. Desain layout rangkaian elektronik

Pada rencana awal pembuatan, meletakkan sensor PIR pada pintu kamar mandi. Namun mendapat saran dari dosen reviewer internal pada saat kegiatan penajaman dan pencermatan pelaksanaan PKM tanggal 4 April 2019, bahwa jika diletakkan di pintu kamar mandi dinilai kurang efektif karena sensor akan mendeteksi semua objek manusia adalah tunanetra sehingga akan mengganggu orang awas saat masuk ke kamar mandi tersebut.

Solusinya yaitu mengganti tempat peletakan sensor di dinding luar kamar mandi. Hal ini karena tunanetra memiliki karakteristik meraba-raba sehingga ketika ada gerakan dalam jarak $-/+5 \mathrm{~cm}$ maka sensor akan memberikan informasi berupa audio informasi kamar mandi yang dapat meuntun tunanetra di kamar mandi.

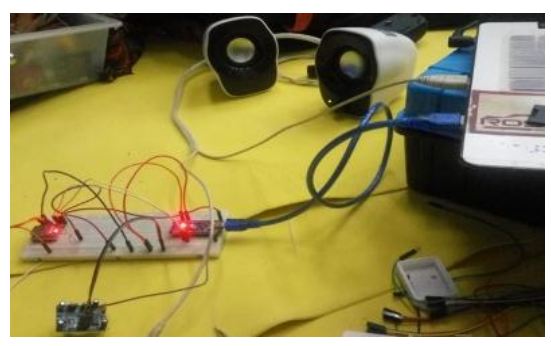

Gambar 3. Pengujian sensor pir

Telah dilakukan pengujian kinerja alat (uji fungsional) dan troubleshooting oleh ketua tim yaitu Raden Budi Santoso. Pada awalnya belum mengatur jarak sensor pir, sehingga ketika ada pergerakan sejauh -/+ $60 \mathrm{~cm}$ sensor sudah dapat mendeteksi obyek yang artinya dengan jarak tersebut sensor belum mampu mendeteksi objek yang benar-benar tunanetra, berdasarkan permasalahan tersebut pelaksana PKM mengatur jarak deteksi sensor pir menjadi I+ $5 \mathrm{~cm}$ karena pada jarak tersebut lebih berpeluang diakses tunanetra dengan cara meraba-raba.

Tabel 1. Uji coba fungsionalitas

\begin{tabular}{ccc}
\hline & Jarak & Hasil \\
\hline Sensor Pir & $-/+60$ & Mendeteksi semua \\
& $\mathrm{cm}$ & $\begin{array}{c}\text { gerakan manusia pada } \\
\text { jarak }-/+60 \mathrm{~cm}\end{array}$ \\
Sensor Pir & $-/+5 \mathrm{~cm}$ & $\begin{array}{c}\text { Hanya mendeteksi } \\
\text { gerakan manusia pada } \\
\end{array}$ \\
& & jarak $-/+5 \mathrm{~cm}$ \\
\hline
\end{tabular}




\section{HASIL DAN PEMBAHASAN}

Pada proses perancangan sistem, peneliti dalam tahap proses merancang cara kerja dari SMARTOBLIN agar dapat berfungsi maksimal dengan berbagai komponen yang digunakan. Pembuatan rangkaian elektronik sesuai dengan kebutuhan kontrol dari SMARTOBLIN. Pada tahap ini mengembangkan yang dirancang langsung dalam bentuk program yang nantinya digunakan sebagai perintah dalam mikrokontroller dengan baik. Secara garis besar sistem hanya terdiri dari empat bagian yaitu bagian utama berupa sensor 1 yang berada di luar kamar mandi, mikrokontroller (arduino), speaker, dan sensor 2 yang berada di dalam kamar mandi.

Tahap pengkodean setelah dilakukan rancangan desain kemudian diterjemahkan menjadi program guna memproses sinyal input yang masuk dari sensor jarak kedalam mikrokontroller (Arduino) sehingga hasil output berupa audio dapat memandu penyandang tunanetra untuk tetap melanjutkan aktivitasnya di kamar mandi. Langkah pengkodean ini dilakukan menggunakan laptop maupun komputer yang telah diinstall software CVAVR. Selain itu, rancangan alat dapat digunakan di berbagai model kamar mandi sehingga alat dapat digunakan dimanapun (portable).

Cara kerja alat yaitu saat objek yaitu tunanetra meraba-raba dinding maka sensor 1 akan mendeteksi objek tersebut dan meneruskan signal ke arduino lalu diproseses menjadi output suara melalui speaker dan memberikan informasi yaitu; 1) kamar mandi ini untuk laki-laki atau perempuan, 2) kamar mandi dalam kondisi diisi atau kosong. Kemudian ketika objek masuk ke kamar mandi sensor 2 mendeteksi dan mengeluarkan suara tetap hati-hati, lantai licin, posisi bak mandi di sebelah kanan dan closet di sebelah kiri. Hasil uji coba terhadap pengguna 4 orang pengguna tunanetra mendapatkan hasil $85 \%$ dengan kategori sangat layak.

Tabel 1. Hasil Kuesioner Manfaat Penggunaan SMARTOBLIN

\begin{tabular}{|c|c|c|c|c|c|c|c|c|c|c|c|c|c|c|}
\hline \multirow[t]{3}{*}{ No } & \multirow[t]{3}{*}{ Pernyataan } & \multicolumn{10}{|c|}{ Tanggapan Pengguna } & \multirow[t]{3}{*}{$\mathbf{N}$} & \multirow[t]{3}{*}{ Skor } & \multirow[t]{3}{*}{ Kategori } \\
\hline & & \multicolumn{2}{|c|}{ SB } & \multicolumn{2}{|r|}{ B } & \multicolumn{2}{|r|}{ CB } & \multicolumn{2}{|c|}{ KB } & \multicolumn{2}{|c|}{ STB } & & & \\
\hline & & f & $\%$ & $\mathbf{f}$ & $\%$ & f & $\%$ & f & $\%$ & f & $\%$ & & & \\
\hline 1 & Item 1 & 2 & $50 \%$ & 2 & $50 \%$ & - & - & - & - & - & - & 4 & 18 & Sangat baik \\
\hline 2 & Item 2 & - & - & 4 & $100 \%$ & - & - & - & - & - & - & 4 & 16 & Sangat baik \\
\hline 3 & Item 3 & 1 & $25 \%$ & 3 & $75 \%$ & - & - & - & - & - & - & 4 & 17 & Sangat baik \\
\hline 4 & Item 4 & 2 & $50 \%$ & 2 & $50 \%$ & - & - & - & - & - & - & 4 & 18 & Sangat baik \\
\hline 5 & Item 5 & 2 & $50 \%$ & 2 & $50 \%$ & - & - & - & - & - & - & 4 & 18 & Sangat baik \\
\hline 6 & Item 6 & - & - & 3 & $75 \%$ & 1 & $25 \%$ & - & - & - & - & 4 & 15 & Sangat baik \\
\hline 7 & Item 7 & 3 & $75 \%$ & 1 & $25 \%$ & - & - & - & - & - & - & 4 & 16 & Sangat baik \\
\hline 8 & Item 8 & 2 & $50 \%$ & 2 & $50 \%$ & - & - & - & - & - & - & 4 & 18 & Sangat baik \\
\hline \multicolumn{13}{|c|}{ Skor } & 136 & - \\
\hline \multicolumn{13}{|c|}{ Rata-rata skor } & 17 & Sangat baik \\
\hline
\end{tabular}

Sehingga didapatkan hasil $\frac{\text { Rata-rata skor }}{\text { Total skor yang diharapkan }} \times 100 \%=\frac{17}{20} \times 100 \%=85 \%$ dengan kategori sangat layak.

\section{KESIMPULAN}

Pelaksanaan program pengembangan ini menghasilkan prototype berupa sistem informasi berbasis audio untuk menuntun tunanetra di kamar mandi yang dikembangkan melalui 4 tahapan berulang yaitu tahap analisis dan studi literatur, desain/perancangan sistem, perakitan sistem elektronik (assemblyelectrnics systems), dan pengujian. Dan mendapatkan hasil $85 \%$ yang diambil dari 4 
orang pengguna tunanetra dengan kategori sangat layak.

\section{DAFTAR PUSTAKA}

Anonim, 2012. Bahaya Selalu Mengincar di Kamar Mandi.

https://health.detik.com/beritadetikhealth/d-1834433/bahaya-selalumengincar-di-kamar-mandi. Diakses 5 Desember 2018

Anonim, 2017. Sudahkah Indonesia Ramah Bagi Para Difabel?. https://kumparan.com/@kumparannews/s udahkah-indonesia-ramah-bagi-paradifable. Diakses 21 Januari 2018

Anonim, 2018. PAM8403 mini board digital power amplifier $5 \mathrm{~V} 2$ channel $3 \mathrm{~W}$. https://www.indo-ware.com/produk-4370pam8403-mini-board- digital power amplifier-5v-2-channel-3w.html. Diakses 21 Oktober 2018.

Anonim, 2018. Pengertian Speaker dan Prinsip Kerjanya.

https://teknikelektronika.com/fungsi-

pengertian-speaker - prinsip - kerja speaker /. Diakses 22 Oktober 2018.

Hallahan, Daniel P, dkk. 2009. Exceptional Learner An Introduction to Special Education. United States of America: PEARSON.

Suharmini, Tin. 2009. Psikologi Anak Berkebutuhan Khusus. Yogyakarta: Kanwa Publisisher. 